\title{
A case report of primary upper urinary tract signet-ring cell carcinoma and literature review
}

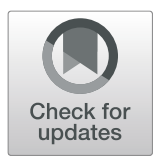

Zhaohua Ye, Qiwu Mi ${ }^{*}$, Daosheng Luo, Zhixiong Li and Jiexin Luo

\begin{abstract}
Background: Upper tract urothelial carcinoma with pure non-urothelial histology is an exception but variants are present in $\sim 25 \%$ of cases. Primary upper urinary tract signet -ring cell carcinoma is extremely rare.

Case presentation: We report the case of a 65-year-old male diagnosed primary upper urinary tract signet-ring cell carcinoma while underwent percutaneous nephrolithotomy. Radical nephroureterectomy and adjuvant chemotherapy were performed sequentially. The patient is now recovering well with a regular follow-up for more than 1 year.

Conclusions: The upper urinary tract malignancy often appears as a high grade, high stage tumor and has a uniformly poor prognosis, but a timely multimodal management can bring a good outcome.
\end{abstract}

Keywords: primary upper urinary tract signet ring cell carcinoma, calculi, percutaneous nephrolithotomy, radical nephroureterectomy

\section{Background}

Upper tract urothelial carcinoma (UTUC) with pure nonurothelial histology is an exception but variants are present in $\sim 25 \%$ of cases $[1,2]$, including squamous cell carcinoma and adenocarcinoma. Among the cases mentioned above, upper urinary tract signet ring cell carcinoma (SRCC) is rare [3, 4]. The upper urinary tract malignancy often appears as a high grade, high stage tumor and has a uniformly poor prognosis [5]. Radical nephroureterectomy (RNU) with bladder cuff removal has been the standard treatment for UTUC [6]. But there is no standard perioperative therapeutic strategy exists for upper urinary tract SRCC because of their rarity.

\section{Case presentation}

A 65-year-old male presented to our hospital with a 30 years history of right flank pain. His pain is a mild and intermittent dull pain, without radiation pain, gross hematuria, fever, urinary frequency or urgency and dysuria. The physical examination was unremarkable.

\footnotetext{
* Correspondence: mqw175@163.com

Department of Urology, Dongguan People's Hospital, Dongguan 523000, China
}

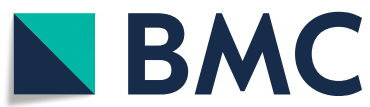

(c) The Author(s). 2020 Open Access This article is licensed under a Creative Commons Attribution 4.0 International License, which permits use, sharing, adaptation, distribution and reproduction in any medium or format, as long as you give appropriate credit to the original author(s) and the source, provide a link to the Creative Commons licence, and indicate if changes were made. The images or other third party material in this article are included in the article's Creative Commons licence, unless indicated otherwise in a credit line to the material. If material is not included in the article's Creative Commons licence and your intended use is not permitted by statutory regulation or exceeds the permitted use, you will need to obtain permission directly from the copyright holder. To view a copy of this licence, visit http://creativecommons.org/licenses/by/4.0/ The Creative Commons Public Domain Dedication waiver (http://creativecommons.org/publicdomain/zero/1.0/) applies to the data made available in this article, unless otherwise stated in a credit line to the data.
167umol/L (normal range 57-111umol/L), CEA, CA-199, and CA72-4 were normal. Abdominal CT demonstrated significant dilatation of the right renal pelvis and the right upper and mid-ureter with multiple calculi. The walls of the renal pelvis and the upper and mid-ureter were thickened with hyperdense soft tissue lesion. (Figure 1)

After three negative urinary cytology examinations, the patient underwent ureteroscopic examination, which showed middle ureteral wall was rough and stenosis with soft tissue mass, but biopsy specimens from this area were non-diagnostic. We tried to insert a double J stent to provide drainage but it failed. Then we recommended a right-sided radical nephroureterectomy but the families refused. They strongly required to the treatment of urinary calculi only. Then a right-side percutaneous nephrolithotomy (PCNL) was performed. Renal access was achieved using B-US guidance with 22-Fr Amplatz sheath. A large amount of white gelatinous material were found in the renal pelvis and taken out for histopathology examination. The calculi were either removed intact or fragmented using a pneumatic lithoclast. A 20Fr Foley catheter was kept as a nephrostomy tube and 


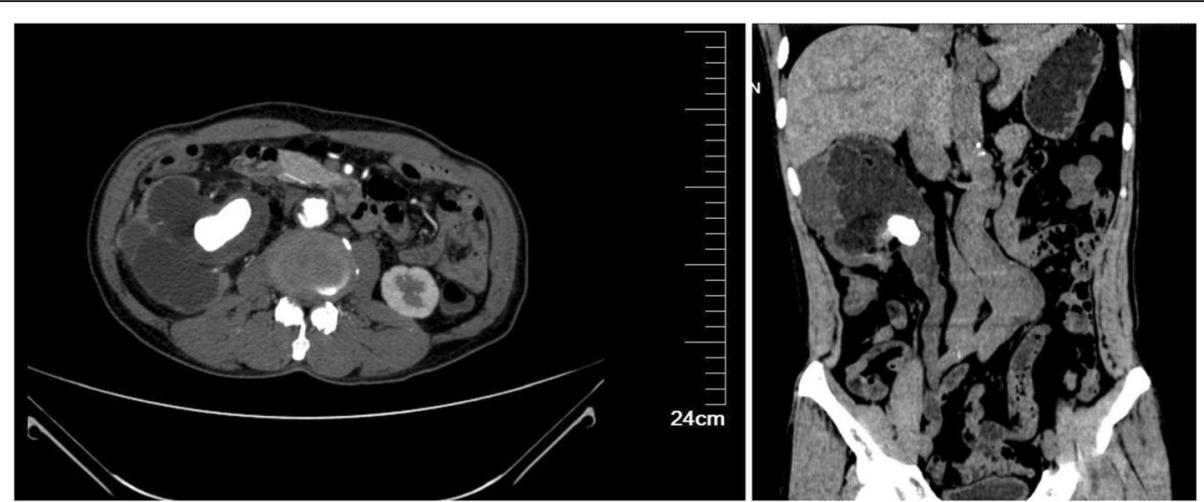

Fig. 1 Abdominal CT demonstrated significant dilatation of the right renal pelvis and the right upper ureter with multiple calculi. The walls of the renal pelvis and the upper and mid-ureter were thickened with hyperdense soft tissue lesion

the catheter balloon was injected with $10 \mathrm{ml}$ saline and pulled to compress the nephrostomy tract (Figure 2). The histopathological examination showed the tumor cells containing intracellular mucin-filled vacuole displacing the hyperchromatic nucleus to one side suggestive of signet ring cell carcinoma (Figure 3). Immunohistochemical examination showed: CK, CK7, CK20, CEA, CDX2 (+), Villin (small +), Vim, GATA3, P53 (-), Ki-67 (about 60\% +).Post-operative PET/CT (18F-FDG8.6mCi as the tracer) showed there was no evidence of further primary malignancy or metastases. Therefore, we considered the tumor as primary upper urinary tract signet ring cell carcinoma. A right-sided RNU with bladder cuff and nephrostomy tract sinus removal were performed subsequently (Figure 4). Histopathology examination found signet-ring cell invaded the renal pelvis, upper ureter and the surrounding adipose tissue through the muscle, the focal nerve and vessels were also involved. Part of the renal pelvis epithelium was presented with obvious intestinal metaplasia and atypical hyperplasia, suggesting the tumor originated from the kidney. Six weeks after the surgery, he received

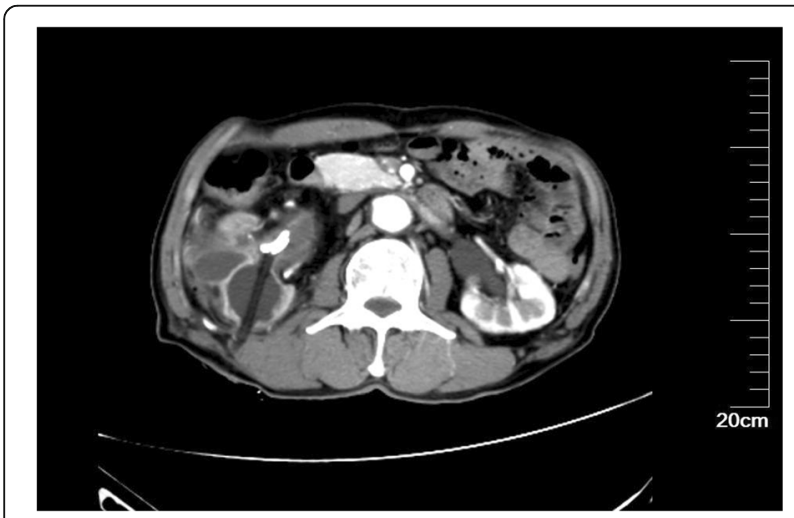

Fig. 2 A 20-Fr Foley catheter was kept as a nephrostomy tube and the catheter balloon was pulled to compress the nephrostomy tract
3 cycles chemotherapy (Gemcitabine $1000 \mathrm{mg} / \mathrm{m} 2$ on days 1 and 8, every 21 days) as adjuvant therapy. 16 months postoperatively, clinical examinations and CT scans showed normal results without metastasis or localized recurrence.

\section{Discussion and conclusion}

Urothelial carcinomas (UCs) are the fifth most common tumors [7], with the UTUC accounting for only $5-10 \%$ $[8,9]$. Approximately $60 \%$ of UTUC are invasive at the time ofdiagnosis. The peak incidence of upper tract urothelial carcinoma occurs in the age from 70 to 90 years old, and the ratio of male to female is about $3: 1$ $[10,11]$. Cases of histologically non-urothelial carcinoma are rare. Among these special cases, squamous cell carcinoma is most frequently reported, and there are variants such as micropapillary carcinoma, sarcomatoid carcinoma, SRCC, etc. Primary SRCC of the urinary tract is a relatively rare. Since primary SRCC of urinary bladder was first described by Saphir in 1955 [12], over 300 cases of urinary tract SRCC have been reported in the English literature, but the report about primary upper urinary tract SRCC is extremely rare. The first example of this variant had been documented by Ekfors and Nurmi in 1988 [13] and there are less than 10 cases so far. SRCC is most commonly found in the gastrointestinal tract. The pathogenesis of SRCC in the urothelium is not yet clear. Referring to the SRCC of urinary bladder, the current hypothesis holds that the signetring cell arising from the glandular metaplasia is caused by chronic inflammation or secondary to the stone stimulation [14-17] or from the totipotential urothelium by direct transition [18-20]. More scholars now support the first hypothesis. For this patient, a history of chronic stone stimulation did exist. Hematuria and flank pain could be the most common symptom at presentation, while a palpable abdominal mass indicates a late stage of the disease. However, it is difficult to distinguish stone 


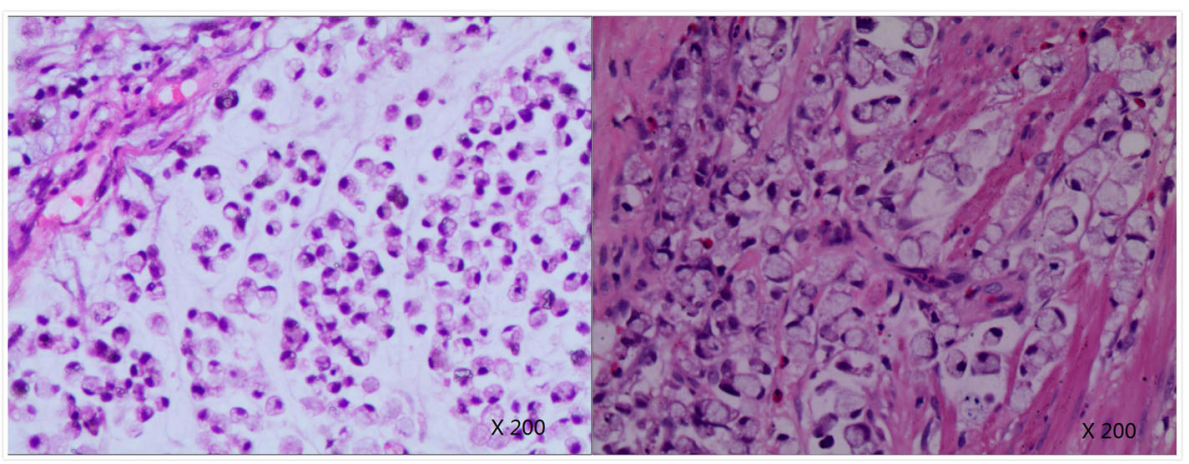

Fig. 3 The histopathological examination showed the tumor cells containing intracellular mucin-filled vacuole displacing the hyperchromatic nucleus to one side suggestive of signet ring cell carcinoma

from tumors only by symptoms and physical examination. Moreover, patients may be asymptomatic [21]. Although hematological oncology examinations are negative in most cases, including our case, abnormality could still be detected from CT scan. Fojecki G et al. concluded that CTU including corticomedullary phase (CMP) is the preferred imaging modality in the diagnostic workup of UTUC [22]. Histopathology is the golden standard for diagnosing UTUC, but there is no consensus which biopsy method is the best to achieve representative samples [23]. Urinary cytology and URS biopsy were negative neither for this patient. Two studies including 762 UTUC patients reported that the percentage of abnormal urothelial cells from preoperative cytology were found in the urine was only about $39 \%[24,25]$. Ureteroscopy is used to visualise the upper urinary tract and biopsy suspicious lesions. Flexible ureteroscopy is more useful with novel digital technology and biopsy device. However, Margolin et al. [26] obtained that the likelihood of missing invasion on URS biopsy was signifcantly increased when the diameter of biopsy fragments

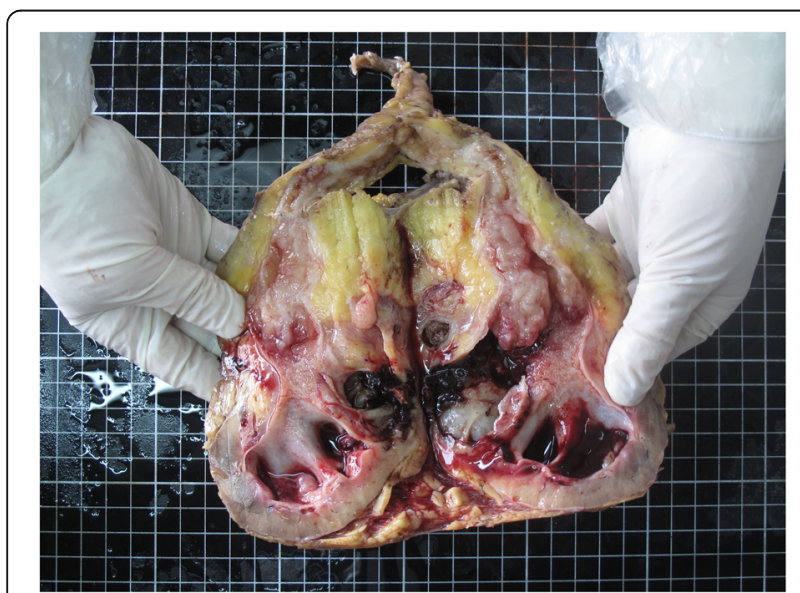

Fig. 4 A right-sided radical nephroureterectomy with bladder cuff and nephrostomy tract sinus removal were performed was smaller than $1 \mathrm{~mm}$. That might be the reason for the false negative diagnosis of this case. This patient was finally diagnosed with upper urinary tract malignancy through PCNL. We had informed the risk and possible complications of PCNL, but the patient's families insisted on kidney-sparing surgery. Admittedly, PCNL is not the most appropriate treatment for this patient, but we had taken the following strategies to avoid the spread of the tumor. Tract dilation was performed in a one-step method rather than a step-by-step method. The pressure and the flow rate of the irrigation fluid were under strict control. The total intraoperative time was 30 mins and the Foley catheter was used as a nephrostomy tube while the balloon was pulled tightly to compress the nephrostomy tract. The histopathological analysis of the specimens from renal pelvis revealed signet-ring cell components. Thus, a secondary SRCC or a rare variant of primary upper urinary tract SRCC was suspected. It is reported that histopathology is one of the method of identification. Stearns et al. described a case of a metastatic, undifferentiated gastric carcinoma, and stated that it grew mainly in adventitial or periureteral tissue without mucosal involvement [27]. Hes $\mathrm{O}$ et al. observed that metastatic cell usually grow in a dissociated manner [28]. In our case, part of the renal pelvis epithelium was presented with obvious intestinal metaplasia and atypical hyperplasia, suggesting the tumor originated from the kidney. Whether immunohistochemical analysis can be useful is still controversial. Singh J et al. described that immunohistochemical staining using CK7 and CK20 could also be helpful in evaluating the cancer's primary origin [29] while Lendorf ME et al. observed that the immunoprofiles of primary urinary SRCC and SRCC arising from the gastrointestinal tract are overlap, including CK7, CK20, CEA, epithelial membrane antigen, CDX2, villin and E-cadherin [30]. Suh $\mathrm{N}$ et al. believed that it is indistinguishable based on histomorphology and immunohistochemistry [31]. Thus, upper gastrointestinal endoscopy and colonoscopy should be 
performed to rule out any eventual primary site. Since the patient refused invasive examination, a PET/CT was performed instead and it showed no evidence of further primary malignancy. Dong MJ et al. reported a case of the false negative ${ }^{18}$ F-FDG PET images of gastric SRCC with right adnexa metastasis. They observed that false negative ${ }^{18}$ F-FDG PET in malignant tumor may be correlated with the pathologic type, differentiation degree and the lesion size [32]. However, there is no case of symptoms of metastatic urinary tract SRCC appearing earlier than those of primary tumors and there is only one case of melanoma where symptoms of ureteral metastasis preceded the recognition of the primary neoplasm [33]. As we are writing, more than one year has passed since the diagnosis, and the patient is well without recurrence or metastasis. Although the followup time is not very long, in our opinion an occult primary tumor is unlikely. The RNU with bladder cuff and nephrostomy tract sinus removal and postoperative adjuvant chemotherapy (AC) was performed subsequently. Perioperative administration of chemotherapeutic agents has been explored for a long time. A phase 3 RCT from multi-institutional collaboration in the UK (POUT study), revealed that AC significantly improves disease-free survival and metastasis-free survival compared to surveillance and chemotherapy given at relapse in patients with UTUC [34]. Cobo-Dols $\mathrm{M}$ et al. [35] and El Ammari JE et al. [36] had respectively reported a success case of primary SRCC of bladder treated with radical cystectomy followed by systemic $\mathrm{AC}$ with cisplatin and gemcitabine. Considering there is no standard AC strategy for upper urinary tract SRCC, we referenced the chemotherapy for SRCC of urinary bladder. Meanwhile, the loss of renal function limited the use of platinum-based drugs, leading us to the administration of gemcitabine alone. According to the follow-up for more than one year after surgery, the prognosis of the patient is favorable. According to the TNM classification 2017 for urothelial carcinoma of the upper urinary tract, the pT3 category renal pelvis tumors are defined as the primary tumor invades beyond muscularis into peripelvic fat or renal parenchyma. Although there is no grading classification for upper urinary tract SRCC, it should be treated as high-grade disease. Thus, a long-term follow-up is still needed for this patient.

Patients with a long history of urinary calculi must be recognized the possibility of urinary tumors and regular workup should be done in order to diagnose the tumor in its early stage. Radiologic findings have a certain effect but non-specific. CTU including CMP is recommended. Histopathological examination is still the golden standard in the diagnosis of tumor occurs. Upper urinary tract SRCC is a rare tumor with a very poor prognosis that requires multimodal management. To plan the optimal therapeutic strategy, it is necessary to rule out a primary malignance outside the urinary tract. Treatment should be performed expeditiously given the aggressive nature of this disease and should include a combination of radical surgery and adjuvant chemotherapy. Prognosis is best predicted by pathologic grade and stage. Continued research is necessary to reveal the severity of this disease and standardize the diagnostic work-up and therapeutic strategy of upper urinary tract SRCC.

\section{Abbreviations \\ SRCC: Signet ring cell carcinoma; PCNL: Percutaneous nephrolithotomy; UTUC: Upper tract urothelial carcinoma; UCs: Urothelial carcinomas; RNU: Radical nephroureterectomy; CTU: Computed tomography urography; AC: Adjuvant chemotherapy}

\section{Acknowledgements}

Zhaohua Ye would like to thank Miss Li Jiaying for her valuable comments.

\section{Authors' contributions}

YZ collected the patient data, analyzed and interpreted the data and wrote the first draft. LZ assisted in data collection and interpretation. MQ, LD and $\sqcup$ reviewed the manuscript and were involved in its critical revision before submission. All authors read and approved the final manuscript.

\section{Funding}

No funding was obtained.

\section{Availability of data and materials}

For further details, the corresponding author can be contacted.

Ethics approval and consent to participate

Not Applicable.

\section{Consent for publication}

Written informed consent was obtained from the patient for publication of this Case Report and any accompanying images. A copy of the written consent is available for review by the Editor of this journal.

\section{Competing interests}

None of the authors has any conflict of interest to disclose

Received: 10 November 2019 Accepted: 18 June 2020

Published online: 26 June 2020

References

1. Rink $M$, Robinson $B D$, Green $D A$, et al. Impact of histological variants on clinical outcomes of patients with upper urinary tract urothelial carcinoma. J Urol. 2012;188(2):398-404. https://doi.org/10.1016/j.juro.2012.04.009.

2. Masson-Lecomte A, Colin P, Bozzini G, et al. Impact of micropapillary histological variant on survival after radical nephroureterectomy for upper tract urothelial carcinoma. World J Urol. 2014;32(2):531-7. https://doi.org/10. 1007/s00345-013-1141-0.

3. Olgac S, Mazumdar M, Dalbagni G. Urothelial carcinoma of the renal pelvis: a clinicopathologic study of 130 cases. Am J Surg Pathol. 2004; 28(12):1545-52.

4. Perez-Montiel D, Wakely PE, Hes $\mathrm{O}$, et al. High-grade urothelial carcinoma of the renal pelvis: clinicopathologic study of 108 cases with emphasis on unusual morphologic variants. Mod Pathol. 2006;19:494-503. https://doi.org/ 10.1038/modpathol.3800559.

5. Delahunt B, Nacey JN, Meffan PJ. Signet ring cell adenocarcinoma of the ureter [J]. Brit J Urol. 1991;68(5):555-6.

6. Roupret $M$, Babjuk $M$, Comperat $E$, et al. European association of urology guidelines on upper urinary tract urothelial carcinoma: 2017 update. Eur Urol. 2018;73(1):111-22.

7. Siggel RL, Miller KD. Cancer statitics, 2016. CA Cancer J Clin. 2016:66:7-30.

8. Siggel RL, Miller KD. Cancer statitics, 2015. CA Cancer J Clin. 2015;65:5-29.

9. Munoz JJ, et al. Upper tract urothelial neoplasms: incidence and survival during the last 2 decades. J Urol. 2000;164:1523. 
10. Shariat SF, et al. Gender differences in radical nephroureterectomy for upper tract urothelial carcinoma. World J Urol. 2011;29:481.

11. Lughezzani G, Sun M, Perrotte P, et al. Gender-related differences in patients with stage I to III upper tract urothelial carcinoma: results from the surveillance, epidemiology, and end results database. Urology. 2010;75:3217. https://doi.org/10.1016/j.urology.2009.09.048.

12. Grignon DJ, Ro JY, Ayala AG, Johnson DE. Signet-ring cell carcinoma of the urinary bladder. Am J Pathol. 1955;31:223-31.

13. Ekfors TO. Primary signet-ring cell carcinoma of the ureter. A case report. APMIS. 1988;96:471-4.

14. Brawer MK, Waisman J. Papillary adenocarcinoma of ureter. Urology. 1982; 19:205-9.

15. Nocks BN, Heney NM, Daly JJ. Primary adenocarcinoma of the urinary bladder. Urology. 1983;21:26-9.

16. Thomas DG, Ward AM, Williams JL. A study of 52 cases of adenocarcinoma of the bladder. Br J Urol. 1971;43:4-15.

17. Ward AM. Glandular neoplasia within the urinary tract. The aetiology of adenocarcinoma of the urothelium with a review of the literature. I. Introduction: the origin of glandular epithelium in the renal pelvis, ureter and bladder. Virchows Arch A Pathol Pathol Anat. 1971;352:296-311.

18. Braun EV, Majid A, Fayemi A, Beaugard E. Primary signet-ring cell carcinoma of the urinary bladder: Review of the literature and report of a case. Cancer. 1981:47:1430-5.

19. Choi H, Lamb S, Pintar K, Jacobs SC. Primary signet-ring cell carcinoma of the urinary bladder. Cancer. 1984;53:1985-90.

20. DeTure FA, Dein R, Hackett RL, Drylie DM. Primary signet-ring cell carcinoma of bladder exemplifying vesical epithelial multipotentiality. Urology. 1975;6: 240-4.

21. Abbas M, Kramer MW, Spieker T, Herrman TR, Merseburger AS, Müller KM, Kuczyk MA, Becker JU, Kreipe HH. Primary mucinous adenocarcinoma of the renal pelvis with carcinoma in situ in the ureter. J Egypt Natl Canc Inst. 2014:26:51-4.

22. Fojecki G, Magnusson A, Traxer O, et al. Consultation on UTUC, Stockholm 2018 aspects of diagnosis of upper tract urothelial carcinoma. World J Urol. 2019;37:2271-8. https://doi.org/10.1007/s00345-019-02732-8.

23. Skolarikos $A$, et al. Cytologic analysis of ureteral washings is informative in patients with grade 2 upper tract TCC considering endoscopic treatment. Urology. 2003:61(6):1146-50.

24. Kobayashi Y, Saika T, Miyaji Y, et al. Preoperative positive urine cytology is a risk factor for subsequent development of bladder cancer after nephroureterectomy in patients with upper urinary tract urothelial carcinoma. World J Urol. 2012;30:271-5. https://doi.org/10.1007/s00345-0110731-y.

25. Tanaka N, Kikuchi E, Kanao K, et al. The predictive value of positive urine cytology for outcomes following radical nephroureterectomy in patients with primary upper tract urothelial carcinoma: a multi-institutional study. Urol Oncol. 2014;32:48.e19-26. https://doi.org/10.1016/j.urolonc.2013.07.003.

26. Margolin EJ, Matulay JT, Li G, et al. Discordance between Ureteroscopic biopsy and final pathology for upper tract Urothelial carcinoma. J Urol. 2018;199:1440-5. https://doi.org/10.1016/j.juro.2018.02.002.

27. STEARNS DB, FARMER DA. Ureteral metastasis secondary to gastric carcinoma: case report. J Urol. 1958;80:214-7.

28. Hes O, Curík R, Mainer K. Urothelial signet-ring cell carcinoma of the renal pelvis with collagenous spherulosis: a case report. Int J Surg Pathol. 2005;13: 375-8.

29. Singh J, Zherebitskiy V, Grynspan D, et al. Metastatic signet ring cell adenocarcinoma of the bladder. Can Urol Assoc J. 2013:6:E15-9.

30. Lendorf ME,Dohn LH,Á Dunga B,et al. An updated review on primary signetring cell carcinoma of the urinary bladder and report of a case. Scand J Urol 2018;52:87-93.DOl:https://doi.org/10.1080/21681805.2017.1418020.

31. Suh N, Yang XJ, Tretiakova MS, Humphrey PA, Wang HL. Value of CDX2, villin, and alpha-methylacyl coenzyme a racemase immunostains in the distinction between primary adenocarcinoma of the bladder and secondary colorectal adenocarcinoma. Mod Pathol. 2005;18:1217-22.

32. Dong MJ, Lin XT, Zhao J, et al. Malignant tumor with false negative 18FFDG PET image. Zhonghua Zhong Liu Za Zhi. 2006;28:713-7.

33. JUDD RL. Melanoma of the ureter: a case report. J Urol. 1962;87:805-7.

34. Birtle AJ, Chester JD, Jones RJ, et al. Results of POUT: A phase III randomised trial of perioperative chemotherapy versus surveillance in upper tract urothelial cancer (UTUC). J Clin Oncol. 2018;36(6_suppl):407.
35. Cobo-Dols M, Alcaide J, Gutiérrez V, et al. Primary signet-ring cell adenocarcinoma of the urinary bladder: a case report. Oncología (Barc). 2006;29:177-80

36. El Ammari JE, Ahsaini $M$, Riyach $\mathrm{O}$, et al. Primary signet-ring cell carcinoma of the urinary bladder successfully managed with cisplatin and gemcitabine: a case report. J Med Case Rep. 2013;7:37. https://doi. org/10.1186/1752-1947-7-37

\section{Publisher's Note}

Springer Nature remains neutral with regard to jurisdictional claims in published maps and institutional affiliations.
Ready to submit your research? Choose BMC and benefit from:

- fast, convenient online submission

- thorough peer review by experienced researchers in your field

- rapid publication on acceptance

- support for research data, including large and complex data types

- gold Open Access which fosters wider collaboration and increased citations

- maximum visibility for your research: over $100 \mathrm{M}$ website views per year

At BMC, research is always in progress.

Learn more biomedcentral.com/submissions 